\title{
Cinnamophilin enhances temozolomide-induced cytotoxicity against malignant glioma: the roles of ROS and cell cycle arrest
}

\author{
Shih-Hang Tai ${ }^{1,2 \#}$, Yu-Wen Lin ${ }^{2 \#}$, Tung-Yi Huang ${ }^{2}$, Che-Chao Chang ${ }^{2}$, Liang-Chun Chao ${ }^{1,2}$, \\ Tian-Shung $\mathrm{Wu}^{3}$, E-Jian Lee $\mathrm{e}^{1,2} \wedge$ \\ ${ }^{1}$ Institute of Clinical Medicine, College of Medicine, National Cheng Kung University, Tainan; ${ }^{2}$ Neurophysiology Laboratory and Department of \\ Surgery, National Cheng Kung University Hospital, College of Medicine, National Cheng Kung University, Tainan; ${ }^{3}$ School of Pharmacy, National \\ Cheng Kung University Hospital, College of Medicine, National Cheng Kung University, Tainan \\ Contributions: (I) Conception and design: SH Tai, EJ Lee; (II) Administrative support: CC Chang, LC Chao; (III) Provision of study materials or \\ patients: TS Wu, EJ Lee; (IV) Collection and assembly of data: YW Lin, TY Huang; (V) Data analysis and interpretation: SH Tai, YW Lin; (VI) \\ Manuscript writing: All authors; (VII) Final approval of manuscript: All authors. \\ \#These authors contributed equally to this work. \\ Correspondence to: Dr. E-Jian Lee, MD, MSc, PhD. 138, Sheng-Li Road, Tainan. Email: ejian@mail.ncku.edu.tw.
}

\begin{abstract}
Background: Temozolomide (TMZ) has been widely used to treat glioblastoma multiforme (GBM). However, many mechanisms are known to quickly adapt GBM cells to chemotherapy with TMZ, leading to drug resistance and expansion of tumor cell populations.

Methods: We subjected human glioblastoma cell lines and an animal model of glioblastoma xenografts with TMZ-based adjuvant treatments to evaluate the synergistic effect of cinnamophilin (CINN), a free radical scavenger.
\end{abstract}

Results: Our results showed that the combined treatment of CINN and TMZ potentiated the anticancer effect and apoptotic cell death in glioma cell lines and enhanced antitumor action in glioma xenografts. TMZ induced reactive oxygen species (ROS) burst and elevated G2 arrest in glioma cells. The CINN-suppressed ROS burst in TMZ-treated glioma cells might be associated with increased apoptosis, as indicated by the upregulation of TUNEL-positive glioma cells. CINN-pretreated glioma cells exhibited increased cyclin B expression and reduced phosphorylation of Cdk1, suggesting reduced G2 arrest in the combined treatment group. Moreover, CINN lowered the protein level of LC3, a hallmark of autophagy, in TMZ-treated cells.

Conclusions: These findings suggest that CINN may restore TMZ toxicity in glioma cancer by suppressing the ROS/G2 arrest pathway.

Keywords: Glioblastoma multiforme (GBM); cinnamophilin; temozolomide; reactive oxygen species; autophagy

Submitted Dec 13, 2020. Accepted for publication Jul 14, 2021.

doi: $10.21037 /$ tcr-20-3426

View this article at: https://dx.doi.org/10.21037/tcr-20-3426

\section{Introduction}

Glioblastoma multiforme (GBM) is the most malignant primary brain tumor in adults. TMZ, an oral alkylating agent, is used as a standard chemotherapeutic drug in patients with GBM after maximal surgical resection (1).
Although TMZ substantially improves the quality of life and prolongs the survival of glioblastoma patients, glioblastoma eventually develops resistance. TMZ increases survival of patients with GBM only by 12 to 14.6 months after diagnosis; thus, there is an urgent requirement for

\footnotetext{
^ ORCID: 0000-0001-9412-7552.
} 
the development of combined medicines for the treatment of $\operatorname{GBM}(2,3)$. In GBM, TMZ induces $\mathrm{O}^{6}$-methylguanine formation and impairs thymine during the subsequent DNA replication cycle, leading to the damage of DNA strands and consequent activation of cell death pathways $(4,5)$. The correction of DNA modification by the repair enzyme O6methylguanine-DNA methyltransferase (MGMT) often causes drug resistance to TMZ (6). Although the MGMTassociated pathway is the main target to overcome TMZ resistance in GBM patients, many other mechanisms have also been targeted to strengthen TMZ cytotoxicity during cancer therapy (7). Several studies have shown that TMZ induces reactive oxygen species (ROS) production during the treatment of GBM, which plays a role in manipulating the cell cycle of cancer cells (8-10). The role of ROS in the development of chemoresistance to TMZ treatment is still under debate.

Studies have confirmed that TMZ-induced accumulation of ROS influences GBM cell viability through various physiological consequences, such as severe DNA damage (11-13), apoptosis (14-16), autophagy $(9,14,17)$, cell cycle arrest $(11,18)$, and cellular senescence. However, whether the shift of glioma cells into G2/M arrest and autophagy is a pro-survival mechanism remains unclear. Studies on resveratrol, an antioxidant, have shown that antioxidant treatment inhibits ROS burst, suppresses autophagy, and augments TMZ-induced apoptosis in glioma cells $(8,9)$. Other studies have suggested that G2 arrest may play a prosurvival role (11). The resveratrol-mediated abrogation of G2 arrest leads to mitotic catastrophe in glioma cells and reinforces TMZ-induced cell senescence. In contrast, data from different types of glioma cells have demonstrated that in TMZ-sensitive cells, cytoplasmic ROS levels contribute to autophagy and cytotoxicity, whereas in TMZ-resistant cells, TMZ fails to induce ROS and autophagy (19). Further studies are warranted to elucidate the role of ROS and downstream cytotoxicity- or resistance-related signaling in glioma treated with TMZ.

We have previously shown that cinnamophilin $\left\{\left[8 R, 8^{\prime} S\right]-\right.$ 4, 4'-dihydroxy-3, 3'-dimethoxy-7-oxo-8, 8'-neolignan; CINN\} isolated from Cinnamomum philippinense is a free radical scavenger that can inhibit ROS production in cells and brain tissue (20-22). Similar to resveratrol, CINN can penetrate the blood-brain barrier and reduce oxidative damage by scavenging toxic free radicals $(22,23)$. Whether CINN can enhance the therapeutic effects of TMZ against brain tumors remains unclear. Identifying the adjuvant effects of antioxidants provides an opportunity to assess the roles of ROS and cell cycle arrest during TMZ therapy. In this study, we aimed to measure ROS levels in glioma cells following a combined treatment of CINN and TMZ. The antitumor efficacy was monitored by the cell viability assay and apoptosis induction using glioma cell lines and a xenograft mouse model following the combined treatment. Additionally, we assessed the changes in cell cycle progression and autophagy after the combined treatment.

We present the following article in accordance with the ARRIVE reporting checklist (available at https://dx.doi. org/10.21037/tcr-20-3426).

\section{Methods}

\section{Chemicals}

Unless otherwise stated, all chemicals were purchased from Sigma-Aldrich Co. (St. Louis, MO, USA). CINN was a generous gift from Dr. Wu (School of Pharmacy, National Cheng Kung University, Tainan City).

\section{Glioblastoma cell culture}

The human glioblastoma cell line U87 MG of unknown origin was obtained from the American Tissue Culture Collection (U87 MG ATCC; RRID: CVCL_0022). The human astrocytoma cell lines U-118 and U373 were gifts provided by Professor Sze (Department of Cell Biology and Anatomy, College of Medicine, National Cheng Kung University, Tainan). Cell lines were maintained in Minimum Essential Medium (MEM)-based culture medium (Gibco; Thermo Fisher Scientific, Inc., Waltham, MA, USA) and cultured in an incubator at $37{ }^{\circ} \mathrm{C}$ and $5 \% \mathrm{CO}_{2}$. The medium was supplemented with $10 \%$ fetal bovine serum (FBS; Gibco; Thermo Fisher Scientific, Inc.), penicillin $(100 \mathrm{U} / \mathrm{mL})$, streptomycin $(100 \mu \mathrm{g} / \mathrm{mL})$, sodium pyruvate $(1 \mathrm{mM})$, and nonessential amino acids $(1 \mathrm{mM}$, Invitrogen, Thermo Fisher Scientific, Inc.). The cells were thawed and grown for a maximum of 20 passages.

\section{Cell viability assay}

Cell viability was evaluated by the 3-(4,5-dimethyl2-thiazolyl)-2,5-dimethyl-2H-tetrazolium bromide (MTT) assay using a commercial kit, according to the manufacturer's instructions. Glioma cells $\left(4 \times 10^{3}\right)$ in $100 \mu \mathrm{L}$ MEM supplemented with $10 \%$ FBS were seeded into a 96well plate and incubated at $37^{\circ} \mathrm{C}$ in a $5 \% \mathrm{CO}_{2}$ humidified 
incubator. After a 24-h incubation, the cells were treated with various TMZ plus CINN concentrations for $72 \mathrm{~h}$. After adding MTT solution $(50 \mu \mathrm{L})$ to the plates, the cells were incubated for $4 \mathrm{~h}$. The supernatants were carefully aspirated, and the formazan crystals were completely solubilized using DMSO. Absorbance was measured at $550 \mathrm{~nm}$ using a Multiskan EX reader (Thermo Scientific, Rockford, IL, USA). The following formula was used to calculate cell viability: percentage cell viability $=($ absorbance of the experimental samples/absorbance of the controls) $\times 100$. The viability of untreated cells was regarded as $100 \%$.

\section{Isobolographic analysis to determine synergy}

Isobolographic analyses of TMZ and CINN were performed according to published protocols $(9,24,25)$. The $\mathrm{IC}_{50}$ values of TMZ and CINN were then calculated and plotted as a percentage of each drug (fractional inhibitory concentration $=$ concentration of TMZ and CINN in combination/concentration of each drug alone). When the sum of the fractions of the two compounds was less than 1 , the combination was considered synergistic, and the graph showed a concave shape.

\section{Animal preparation}

Animal experiments were approved by and conducted under the strict guidelines of the Subcommittee on ResearchAnimal Care of NCKU University Medical Center (approval no. 106112), and the standards met the guidelines for the care and use of animals of Taiwan National Institutes of Health. Fifteen 6-week-old female nude mice (BALB/c nu/ nu) were purchased from the National Laboratory Animal Center for tumor xenograft experiments. Mice were housed in groups in a pathogen-free environment under controlled conditions: $24 \pm 1{ }^{\circ} \mathrm{C}, 60 \%$ humidity, and a $12 \mathrm{~h} \mathrm{light/dark}$ cycle, with ad libitum access to mice chow.

\section{Tumor xenografts}

We subcutaneously injected $5 \times 10^{6}$ U87 MG cells in $0.1 \mathrm{~mL}$ of MEM with $10 \%$ FBS into the right hind flank of 15 female nude mice to induce xenograft tumors. The mice developed visible tumors within three weeks of injection. The tumors were allowed to grow to approximately $60 \mathrm{~mm}^{3}$ to initiate the medical tests. Subsequently, the mice were randomly assigned to control $(n=3), T M Z(n=3), C I N N$ $(\mathrm{n}=3)$, and TMZ plus CINN ( $\mathrm{n}=6)$ groups and injected with saline and $45 \%$ aqueous hydroxypropyl-cyclodextrin (HPCD; Sigma Chemical Co., St Louis, MO, USA), HPCD and TMZ (10 mg/kg), saline and CINN (80 mg/kg), and a combination of TMZ $(10 \mathrm{mg} / \mathrm{kg})$ and CINN (80 mg/kg), respectively, for 15 days. The tumor volume and body weight were measured once every two days, starting from the first day of treatment. Tumor volumes were calculated as previously described (25): tumor volume $=(4 \pi / 3) \times(\text { width } / 2)^{2} \times($ length $/ 2)$.

\section{ROS measurement}

The intracellular ROS $\mathrm{H}_{2} \mathrm{O}_{2}$, and $\mathrm{O}_{2}{ }^{-}$were quantified by labeling dihydrorhodamine-123 (DHR-123) and dihydroethidium (DHE), respectively, by flow cytometric analysis. U87 MG cells were treated with TMZ or CINN in MEM with $10 \%$ FBS for $72 \mathrm{~h}$. The cells were then harvested by trypsinization, followed by centrifugation and resuspension in phosphate-buffered saline (PBS), and stained with $5 \mu \mathrm{M}$ DHR123 and $10 \mu \mathrm{M}$ DHE for $30 \mathrm{~min}$ at $37^{\circ} \mathrm{C}$ in the dark. The cell populations were gated according to the FSC/SSC scatter on a FACS Calibur cytometer (BD Biosciences, San Jose, CA, USA). Data were analyzed using the CellQuest software (BD Biosciences). The percentage increase in the fluorescence peak represents the level of ROS production.

\section{Comet assay}

U87 MG cells were treated with TMZ, CINN, or combinations of both for 48 and $72 \mathrm{~h}$. After drug treatment, cells were harvested to examine DNA damage using the comet assay (single-cell gel electroporesis), as previously described $(26,27)$. Cells were washed with PBS and mixed with low-melting agarose $(1: 10)$ before being loaded onto microscope slides. Cell lysis was performed at $4{ }^{\circ} \mathrm{C}$ (alkaline comet assay) and $37^{\circ} \mathrm{C}$ (neutral comet assay). After electrophoresis for $25 \mathrm{~min}$ at $25^{\circ} \mathrm{C}$, DNA was stained with DAPI and imaged using a Zeiss Axioskop 2 Mot microscope equipped with a digital camera (CoolSnap-Pro, Media Cybernetics, Carlsbad, CA, USA). DNA damage was determined by the cell head length or cell tail length $(\mu \mathrm{m})$ and the percentage of DAPI-stained comet cells using the Image $\mathrm{J}$ and Open Comet 1.3 software. These experiments were repeated at least three times, with an average of 200 cells each time. 


\section{Terminal deoxynucleotidyl transferase-mediated dUTP nick end labeling (TUNEL) assay}

The TUNEL assay was performed using an in situ cell death detection kit according to the manufacturer's protocol (Calbiochem, Merck Biosciences, Bad Soden, Germany). Cells were seeded onto polyline-precoated coverslips for $24 \mathrm{~h}$ before treating with TMZ plus CINN for $24 \mathrm{~h}$. Then, the cells were fixed with $4 \%$ paraformaldehyde prepared in $0.1 \mathrm{M}$ PBS, followed by treatment with $3 \% \mathrm{H}_{2} \mathrm{O}_{2}$ at room temperature for $5 \mathrm{~min}$. The cells were digested with freshly diluted proteinase $\mathrm{K}(1: 200)$ at room temperature for $10 \mathrm{~min}$. The TdT equilibration buffer was then added at room temperature for $30 \mathrm{~min}$, the cells were maintained in the TdT labeling reaction mixture at $37^{\circ} \mathrm{C}$ for $2 \mathrm{~h}$ in the dark, and the nuclei were stained with DAPI for an examination under a fluorescence microscope at $200 \times$ magnification. The results are presented as the ratio of TUNEL-positive cells to the total number of counted cells.

\section{Cell cycle analysis}

After treating U87 MG cells with TMZ, CINN, or combinations of both, their cell cycle distribution was assessed by flow cytometry following propidium iodide (PI) staining. The cells were collected after trypsinization and centrifugation at the indicated time points. The cell pellets were washed twice with Tris-buffered saline (TBS; J.T. Baker, Thermo Fisher Scientific, Inc.) and fixed in ice-cold $70 \%$ ethanol at $4{ }^{\circ} \mathrm{C}$ overnight. Cells were resuspended at room temperature for $30 \mathrm{~min}$ in TBS containing $500 \mu \mathrm{g} / \mathrm{mL}$ of RNase A and stained with PI $(10 \mu \mathrm{g} / \mathrm{mL})$ for $30 \mathrm{~min}$ at room temperature in the dark. Cell cycle distribution was analyzed using a FACSCalibur flow cytometer (Becton Dickinson, San Jose, CA, USA). The DNA histograms were further evaluated using the CellQuest software (Becton Dickinson) on a Power Macintosh 7,300/200 computer to calculate the percentage of cells in various cell cycle phases.

\section{Western blotting}

Protein sample preparation and immunoblotting were performed as previously described (28). Cells were lysed with lysis buffer containing $1 \%$ Triton X-100, $20 \mathrm{mM}$ Tris-HCl (pH 7.5), $150 \mathrm{mM} \mathrm{NaCl}, 0.5 \%$ deoxycholate, $1 \mathrm{mM}$ EDTA, and $0.1 \%$ sodium dodecyl sulfate. The samples were collected after centrifugation at $18,000 \times g$ for 60 min at $4{ }^{\circ} \mathrm{C}$. After mixing with sodium dodecyl sulfate buffer and heating at $100{ }^{\circ} \mathrm{C}$ for $10 \mathrm{~min}$, the protein concentrations were determined using a BCA protein assay kit (Thermo Scientific). For western blotting, samples $(40 \mu \mathrm{g})$ were loaded and separated by sodium dodecyl sulfate-polyacrylamide gel electrophoresis, transferred onto polyvinylidene difluoride microporous membranes (PVDF, Millipore, Billerica, MA, USA), and blocked in $5 \%$ milk prepared in Tris-buffered solution ( $\mathrm{pH}$ 7.6). The membranes were incubated with primary antibodies against LC3 (cat. No. PM036; 1:100; MBL, Nagoya, Japan), cyclin B (cat. No. GTX100911; 1:1,000; GeneTex, Taipei, Taiwan), pCdk1 (Y15; cat. No. GTX; 128155; 1:1,000; GeneTex), cleaved caspase 3 (cat. No. 9664S; 1:1,000; Cell Signaling Technology, Inc., Danvers, MA, USA), caspase 3 (cat. No. 9662; 1:1,000; Cell Signaling Technology), and $\beta$-actin (cat. No. MAB1501; 1:10,000; EMD Millipore; Merck KGaA, Darmstadt, Germany) and then diluted in blocking buffer at $4{ }^{\circ} \mathrm{C}$ overnight. Finally, the membranes were incubated with horseradish peroxidase-conjugated anti-rabbit or antimouse IgG (cat. No. 111-035-144/115-035-003; 1:5,000; Jackson ImmunoResearch, West Grove, PA, USA). Bound antibodies were visualized using the Amersham ECL system (GE Healthcare Bio-Sciences Corp., Piscataway, NJ, USA). A luminescent image analyzer (Fujifilm LAS-3000; Fuji Photo Film Co., Tokyo, Japan) was used to measure the optical density.

\section{Immunobistochemistry for $\mathrm{LC} 3$}

U87 MG cells were seeded onto polyline-precoated coverslips for $24 \mathrm{~h}$ and treated with TMZ, CINN, or combinations of both for $72 \mathrm{~h}$. Then, the cells were fixed in $4 \%$ paraformaldehyde in PBS for $20 \mathrm{~min}$ at room temperature, permeabilized in PBS supplemented with $0.5 \%$ Triton X-100 and 5\% FBS, and incubated with the primary antibody LC3 prepared in blocking buffer $(1: 100)$ at $4{ }^{\circ} \mathrm{C}$ overnight. After washing with PBS, the cells were incubated with goat anti-mouse IgG conjugated with fluorescein (FITC; cat. No.715-096-151, 1:5,000; Jackson ImmunoResearch, West Grove, PA, USA). The cell nuclei were stained with DAPI Fluoromount $\mathrm{G}^{\circledR}$ (SouthernBiotech, Birmingham, AL, USA) and examined under a fluorescence microscope (Olympus IX71, Olympus Optical Co. Ltd, Tokyo, Japan). The fluorescence images illustrating FITC (green) and DAPI (blue) staining were superimposed using Image-Pro Plus 5.1 (Media Cybernetics, Silver Spring, MD, USA). 


\section{Statistical analysis}

Data are presented as the mean \pm standard deviation of the mean. The significance of the difference between means was assessed by one-way analysis of variance (one-way ANOVA) with Fisher's protected least significant difference (LSD) post hoc comparison. Statistical significance was set at $\mathrm{P} \leq 0.05$.

\section{Results}

\section{CINN- and TMZ-induced cytotoxicity in different cell lines}

Human glioblastoma cell lines, U87 MG, U-118, and U373, were challenged with TMZ and CINN at concentrations ranging from 4 to $1,000 \mu \mathrm{M}$ for $72 \mathrm{~h}$ to perform the MTT assay. As shown in Figure 1, TMZ and CINN alone decreased viability of all types of glioma cells in a dosedependent manner. The $\mathrm{IC}_{50}$ values (concentration resulting in cell viability of $50 \%$ in control) of TMZ and CINN were 849.32 and $375.52 \mu \mathrm{M}$, respectively, in U87 MG cells. TMZ (100 and $200 \mu \mathrm{M})$ and CINN (20, 50, and $100 \mu \mathrm{M})$ slightly decreased cell viability in cultured cells. Based on these observations, we selected the U87 MG cell line to test these concentrations of TMZ and CINN to evaluate the synergistic effects on cytotoxicity.

\section{CINN effectively enhanced the cytotoxicity of TMZ by increasing DNA damage and apoptosis}

Treatment of U87 MG cells with TMZ plus CINN significantly improved cell toxicity compared to CINN or TMZ alone (Figure $2 A ; \mathrm{P} \leq 0.05$ ). Isobolographic analysis was conducted to determine the synergistic effect and confirm that CINN sensitizes U87 MG cells to TMZinduced cytotoxicity (Figure $2 B$ ). The $\mathrm{IC}_{50}$ values derived from different concentrations of TMZ (100 and $200 \mu \mathrm{M})$ and CINN $(20,50$, and $100 \mu \mathrm{M})$ are shown in Figure $2 B$. The $\mathrm{IC}_{50}$ of CINN was approximately 137 or $103 \mu \mathrm{M}$ when combined with TMZ. TMZ (100 and $200 \mu M)$ combined with CINN was significantly lower than that of TMZ alone (849.32 $\mu \mathrm{M})$, suggesting that CINN can sensitize U87 MG cells to TMZ.

\section{Combined treatment of CINN and TMZ reduced the growth of glioma xenografts}

To investigate the synergistic inhibition of tumor growth by
CINN and TMZ in vivo, we generated tumor xenografts by subcutaneously injecting U87 MG cells into immunodeficient mice. As demonstrated in Figure $2 C$ (left panel), vehicletreated mice exhibited tumors that grew to an average size of $3.50 \mathrm{~cm}^{3}$ within 15 days. Mice treated with TMZ or CINN alone experienced a moderate decrease in tumor volume compared to the control. However, the tumor volumes in the TMZ plus CINN-treated groups were not significantly lower. Significant reduction in tumor volumes was observed on day 15 in the TMZ plus CINN-treated groups compared with the vehicle group. On day 15 , the tumor size in the TMZ plus CINN-treated group was approximately $0.7 \mathrm{~cm}^{3}$, whereas, in the TMZ-treated group, the average tumor size was $2.4 \mathrm{~cm}^{3}$. Figure $2 C$ (right panel) shows the typical xenografts. The average tumor weight in TMZ plus CINNtreated mice was lower than that in TMZ-treated mice. Our data indicate that combined treatment of TMZ and CINN was therapeutically effective in vivo.

\section{CINN reduced TMZ-mediated ROS production}

Our previous studies showed that CINN inhibited ROS burst by reducing $\mathrm{O}_{2}{ }^{-}$and $\mathrm{H}_{2} \mathrm{O}_{2}$ production $(21,22,29)$. We examined whether CINN was also able to inhibit TMZinduced ROS burst in U87 MG cells. After treatment with $100 \mu \mathrm{M} \mathrm{TMZ}, \mathrm{O}_{2}^{-}$and $\mathrm{H}_{2} \mathrm{O}_{2}$ levels significantly increased in U87 MG cells compared to the vehicle control (Figure 3; $\mathrm{P} \leq 0.05$ ). However, treatment with $50 \mu \mathrm{M}$ CINN for $1 \mathrm{~h}$ considerably reduced $\mathrm{O}_{2}^{-}$and $\mathrm{H}_{2} \mathrm{O}_{2}$ levels (2.3- and 3.4fold, respectively) in U87 MG cells compared with TMZ alone. Furthermore, $100 \mu \mathrm{M}$ CINN did not increase the suppression of TMZ-induced ROS burst, which indicated that $50 \mu \mathrm{M}$ CINN was sufficient to eliminate most of the TMZ-induced ROS production.

\section{CINN effectively enhanced TMZ cytotoxicity by increasing DNA damage and apoptosis}

We investigated the effect of CINN on TMZ-induced cytotoxicity in U87 MG cells. Figure $4 A$ shows the results of the comet assay, a sensitive method to investigate DNA damage; in particular, it identifies individual apoptotic cells with highly fragmented DNA. When U87 MG cells were subjected to the combined treatment, the percentage of damaged cells that exhibited the comet tail along the cell body increased 1.6-fold, while the tail length increased up to 1.4-fold when compared with TMZ treatment alone (Figure $4 A ; \mathrm{P} \leq 0.05$ ). Similarly, the level of cleaved caspase 3 
A

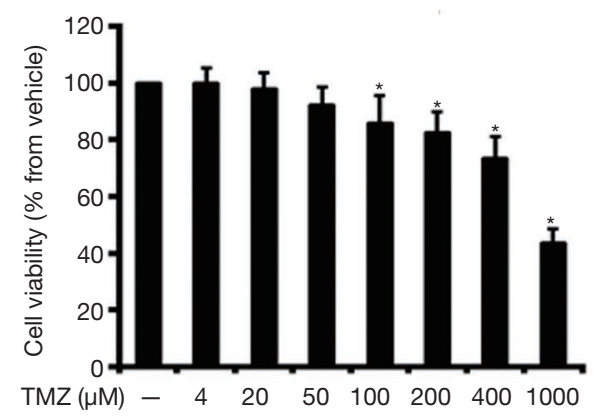

B

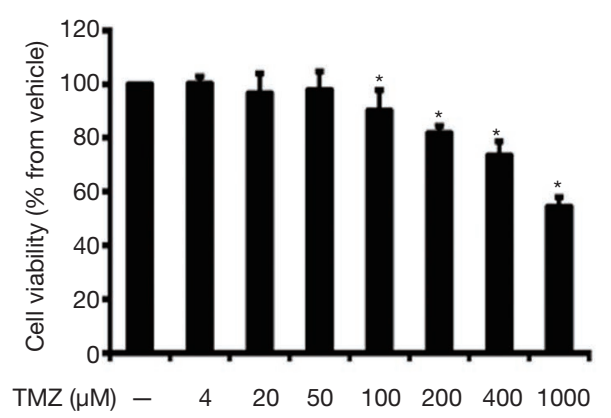

C

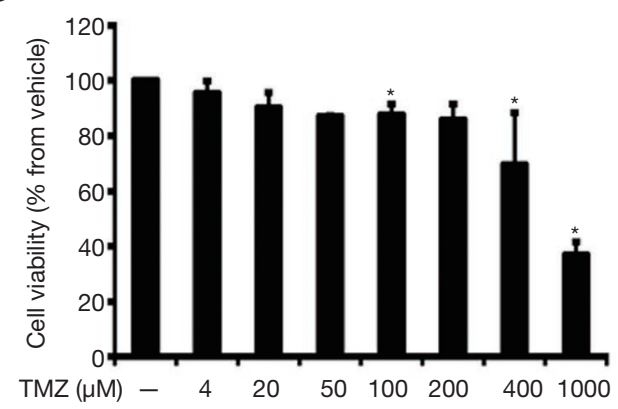

U87MG

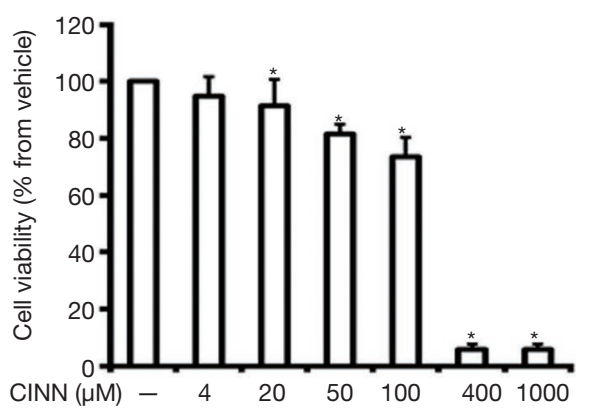

U118

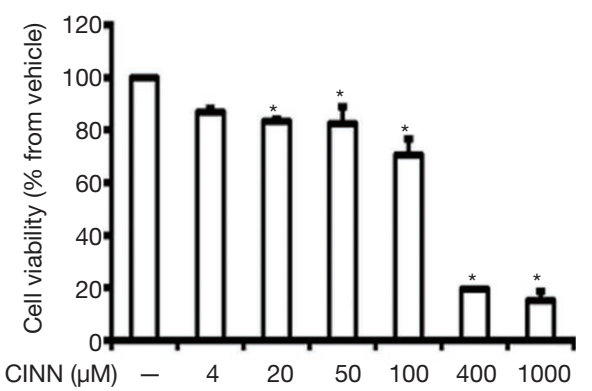

U373

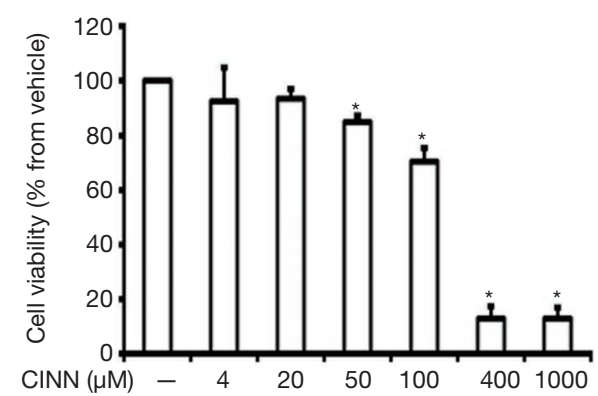

Figure $1 \mathrm{TMZ}$ and CINN reduced glioma cell viability in a dose-dependent manner. The cytotoxicity of TMZ (left panel) and CINN (right panel) at concentrations ranging from of 4 to $1,000 \mu \mathrm{M}$ for $72 \mathrm{~h}$ in the U87 MG (A), U-118 (B), and U373 (C) cell lines were determined by MTT assay. *, $\mathrm{P} \leq 0.05$ compared with vehicle-treated cells. $\mathrm{n}=3$ for primary neuron cells and $\mathrm{n}=4$ for U87 MG cells.

was higher in TMZ plus CINN-treated cells than in TMZtreated cells (Figure 4B; $\mathrm{P} \leq 0.05$ ). Moreover, the percentage of TUNEL-positive cells, an indication of apoptosis, was significantly greater in the TMZ plus CINN-treated group than in the groups treated with TMZ or CINN alone (Figure $4 C ; \mathrm{P} \leq 0.05$ ). These results demonstrate that CINN can enhance TMZ-induced DNA damage and apoptosis.

\section{CINN suppressed TMZ-induced cell cycle arrest}

Previous studies have demonstrated that TMZ-induced
ROS participate in the regulation of cell cycle arrest in glioma cells $(9,11,30,31)$. We investigated whether CINN causes G2/M arrest in TMZ-treated U87 MG cells by DNA flow cytometry. We confirmed that TMZ treatment $(100 \mu M)$ substantially increased the number of U87 MG cells in the G2/M phase and reached a plateau between 48 and $72 \mathrm{~h}$ (Figure 5A). CINN reversed TMZ-induced cell cycle distribution by reducing the cell population in the $\mathrm{G} 2 / \mathrm{M}$ phase at a time window between 48 and $72 \mathrm{~h}$ of treatment. The majority of U87 MG cells (approximately $40 \%$ of total cells) in G2 arrest shifted to other phases in the 

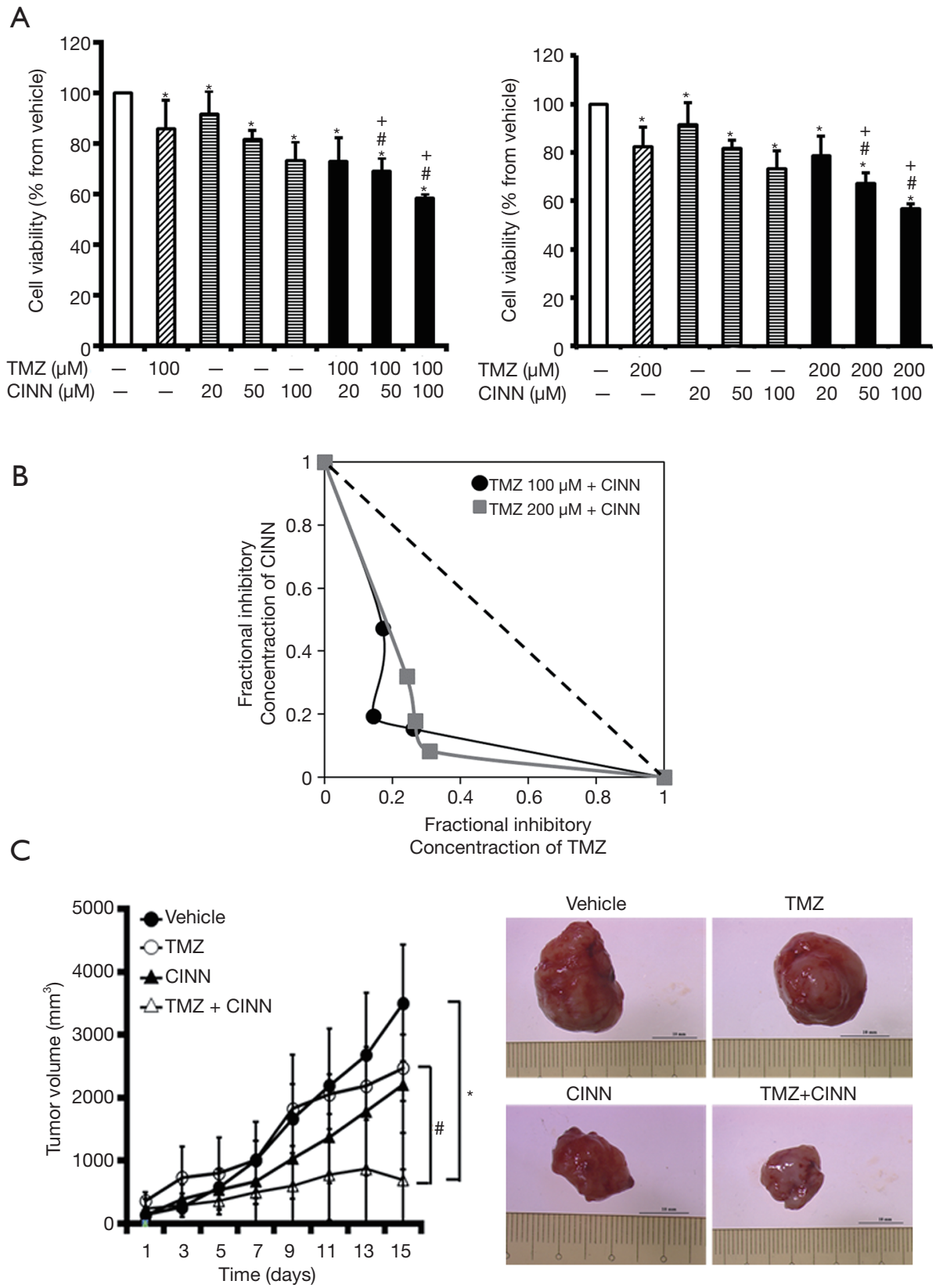

Figure 2 CINN enhanced TMZ-induced cytotoxicity in human glioma cells and the xenograft model. (A) U87 MG cells were treated with indicated doses of TMZ, CINN, or combinations of both for $72 \mathrm{~h}$. The effects of the drugs on the viability of U87 MG cells were determined by MTT assay. $\mathrm{n}=6$ for $\mathrm{U} 87 \mathrm{MG}$ cells. (B) The $\mathrm{IC}_{50}$ values of each drug in combination and the synergistic effects were determined by isobolographic analysis. Isobolographic analysis of TMZ at 100 and $200 \mu M$ was carried out separately. The dotted line on the diagram represents the combined effects of the two drugs, indicating it is additive. (C) Mice with U87 MG xenografts were injected every day with $2 \mathrm{mg} / \mathrm{kg}$ TMZ, $80 \mathrm{mg} / \mathrm{kg}$ CINN, or combinations of both, and the tumor volume was measured. At the end of the experiment (15 days), tumor tissues were excised from each mouse. *, $\mathrm{P} \leq 0.05$ compared with vehicle-treated cells; ${ }^{\text {* }}, \mathrm{P} \leq 0.05$ compared with TMZtreated cells; ${ }^{+}, \mathrm{P} \leq 0.05$ compared with CINN-treated cells. 


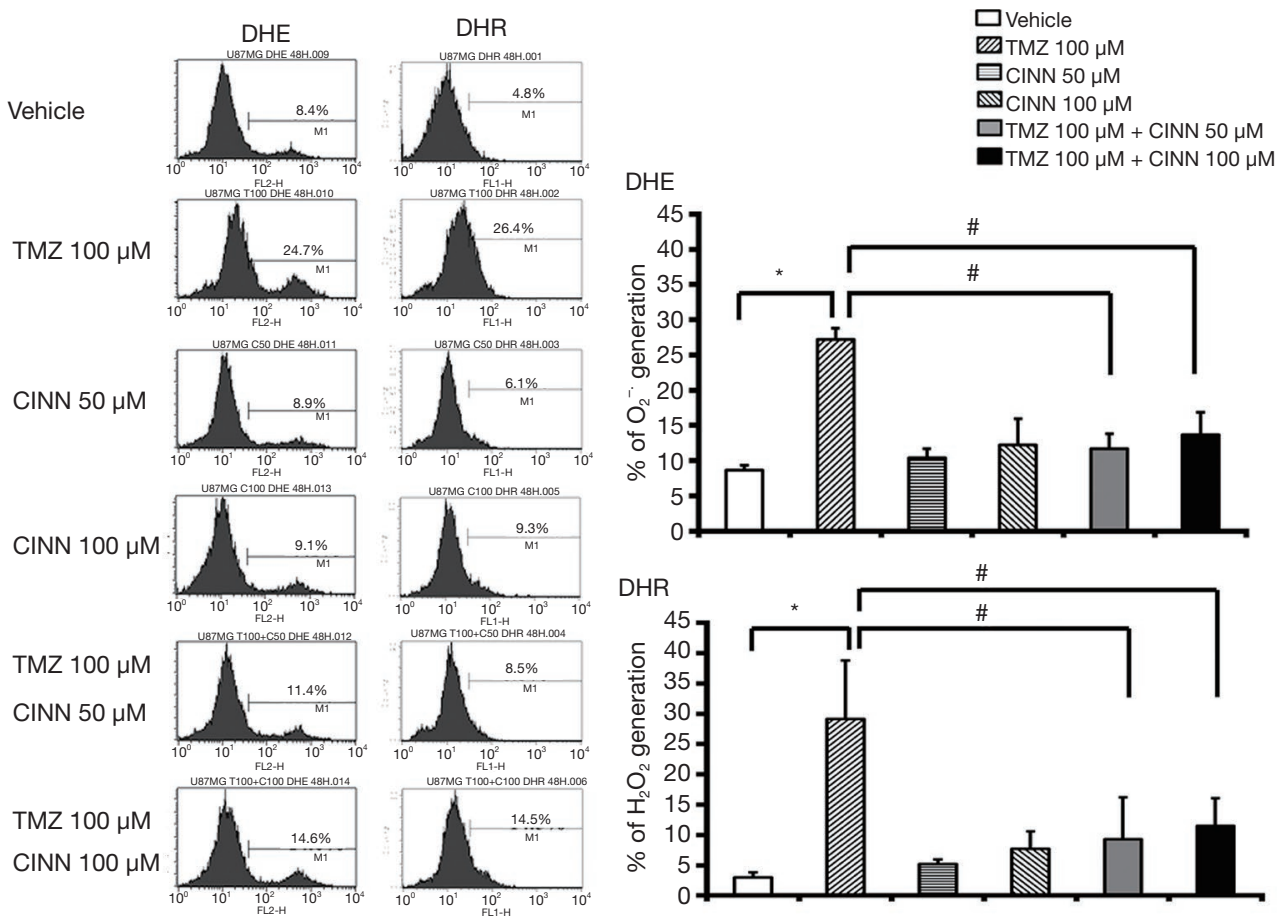

Figure 3 CINN suppressed TMZ-induced ROS production in human glioma cells. U87 MG cells were pretreated with or without CINN $(50 \mu \mathrm{M})$ for $1 \mathrm{~h}$ followed by TMZ $(100 \mu \mathrm{M})$ for $72 \mathrm{~h}$, and then analyzed by DHE and DHR-123 staining by flow cytometry. *, P $\leq 0.05$ compared with vehicle-treated cells; ${ }^{*}, \mathrm{P} \leq 0.05$ compared with TMZ-treated cells. $\mathrm{n}=4$ for U87 MG cells.

presence of TMZ $(100 \mu \mathrm{M})$ plus CINN $(50 \mu \mathrm{M})$ between 48 and $72 \mathrm{~h}$. Increasing the concentration of CINN to $100 \mu \mathrm{M}$ in the combined treatment did not further reduce the cell population in the G2/M phase when compared to $50 \mu \mathrm{M}$ CINN (data not shown); this result was consistent with that from ROS level analysis (Figure 3). The expression levels of cyclin B and phosphorylation of cyclin-dependent kinase 1, which are G2/M checkpoint and G1/S regulatory proteins, were determined by western blotting. After U87 MG cells were treated with TMZ for 12 and $24 \mathrm{~h}$, the expression of cyclin B decreased, while the level of Cdk1 phosphorylation increased (Figure 5B). Nevertheless, the changes in TMZ-induced cell cycle regulators in U87 MG cells between 12 and $24 \mathrm{~h}$ were reversed after combined treatment (TMZ plus CINN at 100 and $50 \mu \mathrm{M}$ ), with a substantial increase in cyclin B expression by 2.7 - and 2-fold, and a decrease in phosphorylation of cyclin-dependent kinase 1 by approximately $38 \%$ (Figure $5 B ; \mathrm{P} \leq 0.05$ ). It is worth mentioning that the differences in regulatory proteins appeared $12 \mathrm{~h}$ before the differences in cell cycle distributions between the TMZ alone and TMZ plus CINN treatments, suggesting a cause-effect relationship between regulatory proteins and cell cycle events.

\section{CINN reduced TMZ-induced autophagy in buman glioma cells}

To investigate the effect of CINN on TMZ-induced autophagy in U87 MG cells, we measured LC3 protein levels by western blotting and immunofluorescence staining. U87 MG cells were pretreated with or without CINN $(50 \mu \mathrm{M})$ for $1 \mathrm{~h}$, followed by TMZ (100 or $200 \mu \mathrm{M})$. Cell lysates were collected at the indicated times and analyzed by immunoblotting with antibodies against LC3 or $\beta$-actin. The combined treatment of TMZ and CINN lowered $(\mathrm{P} \leq 0.05)$ LC3-II protein expression after 12 and 24 h compared with TMZ alone (Figure $6 A$ ). Immunofluorescence staining also revealed a reduction in LC3 staining in U87 MG cells upon combined treatment (Figure 6B).

\section{Discussion}

Many TMZ-based adjuvant treatments have been proposed 
A

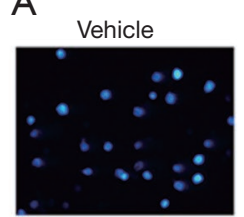

CINN $100 \mu \mathrm{M}$

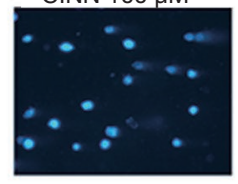

B

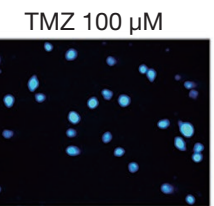

TMZ $100 \mu \mathrm{M}$ CINN $100 \mu \mathrm{M}$
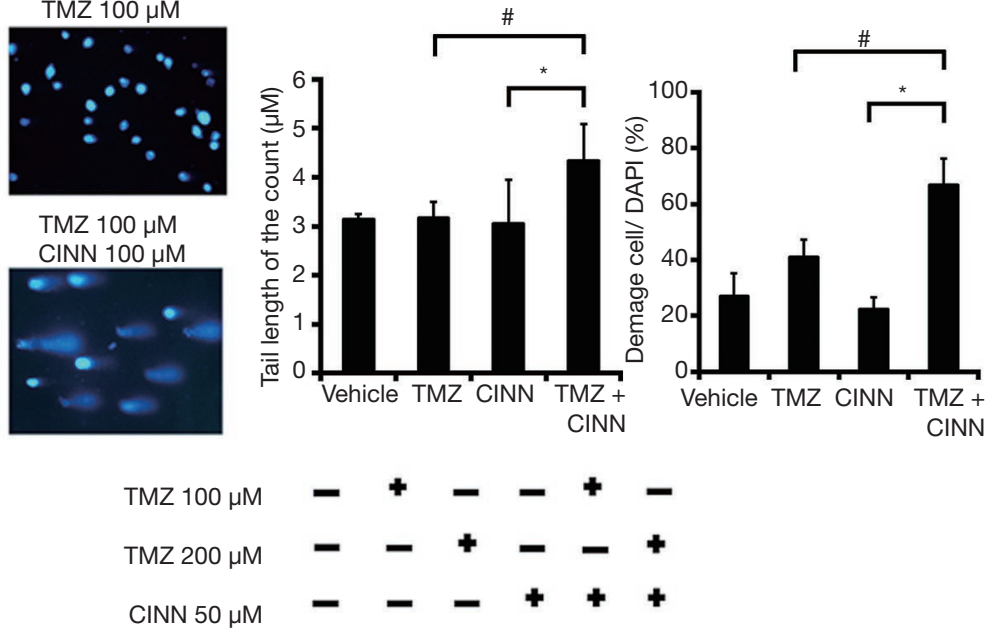

Cleaved Caspase 3
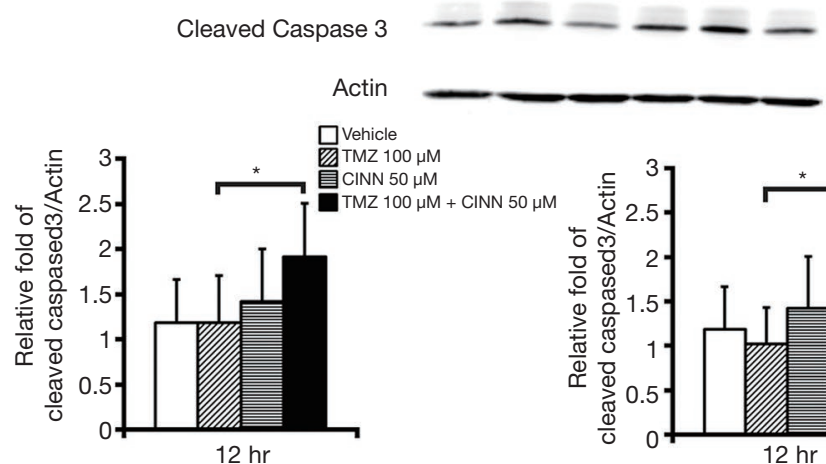

C

$$
\text { Vehicle }
$$
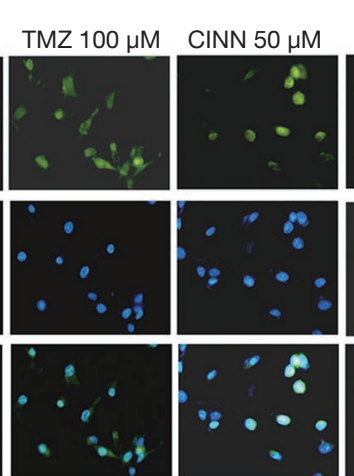

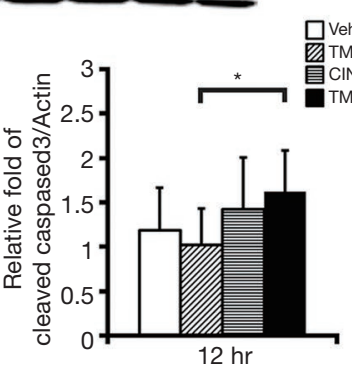

TMZ $100 \mu \mathrm{M}$

CINN $50 \mu \mathrm{M}$
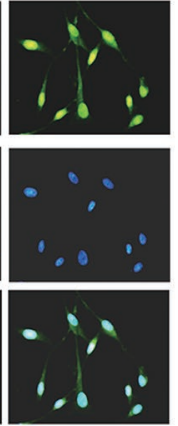

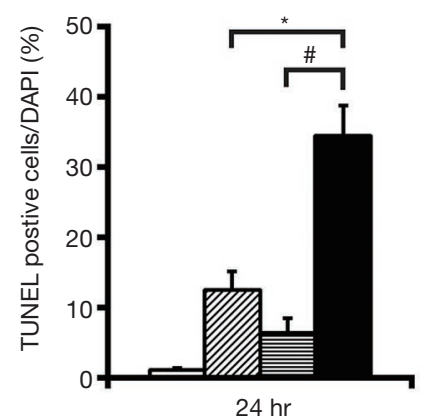

Figure 4 The combined administration of CINN and TMZ induced DNA damage and apoptosis in human glioma cells. (A) U87 MG cells were pretreated with or without CINN $(100 \mu \mathrm{M})$ for $1 \mathrm{~h}$, followed by TMZ $(100 \mu \mathrm{M})$ for $72 \mathrm{~h}$. The effect of DNA damage was detected by the comet assay. Representative microphotographs of cells subjected to the comet assay and stained with DAPI (blue, 400×) are shown in the left panel. $\mathrm{n}=3$ for U87 MG cells. (B) U87 MG cells were pretreated with or without CINN (50 $\mu$ M) for $1 \mathrm{~h}$, followed by TMZ (100 or $200 \mu \mathrm{M}$ ) for 12 and $24 \mathrm{~h}$. The effects of drug-induced apoptosis were evaluated using caspase 3. (C) TUNEL assay was used to investigate U87 MG cell apoptosis (blue: DAPI, green: TUNEL, 400×). *, P $\leq 0.05$ compared with TMZ-treated cells; ", $\mathrm{P} \leq 0.05$ compared with CINNtreated cells. $\mathrm{n}=6$ for immunoblotting and $\mathrm{n}=3$ for TUNEL assay. 
A

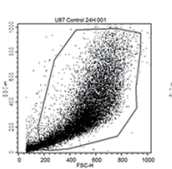

Control

$24 \mathrm{~h}$

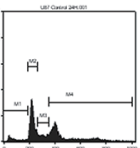

$48 \mathrm{~h}$

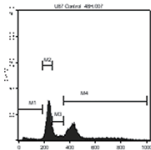

$72 \mathrm{~h}$

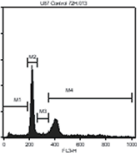

B
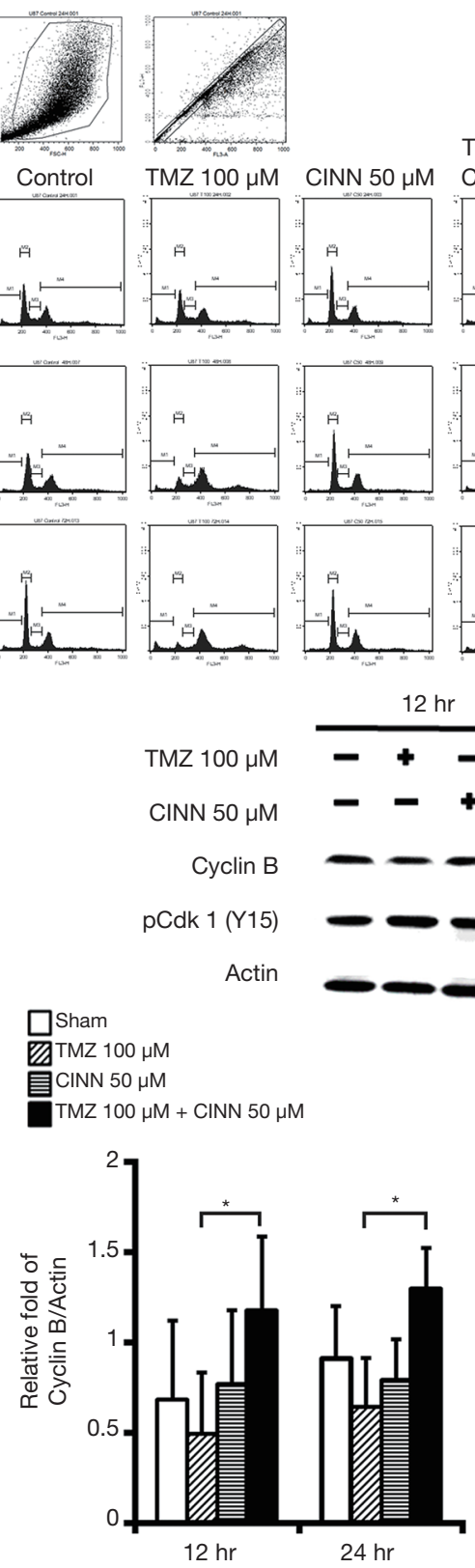

$\square$ Sham
TMZ $100 \mu \mathrm{M}$ CINN $50 \mu \mathrm{M}$
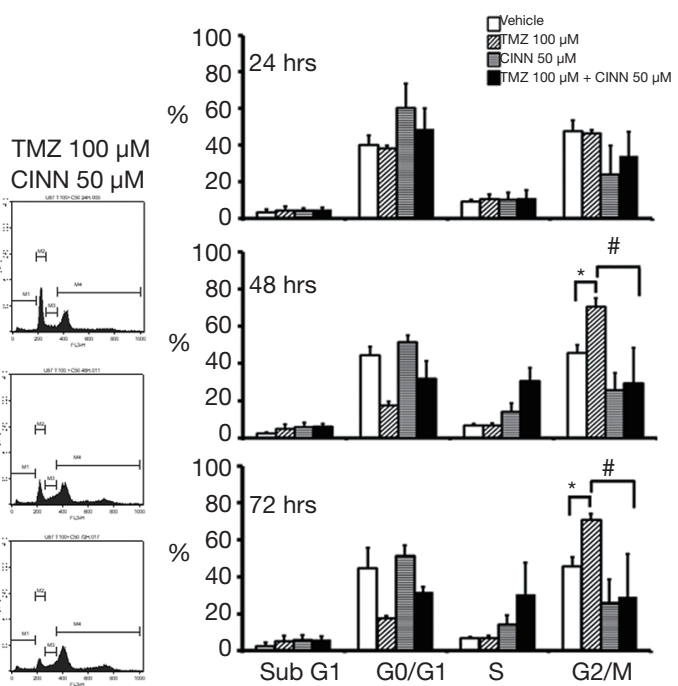

$24 \mathrm{hr}$

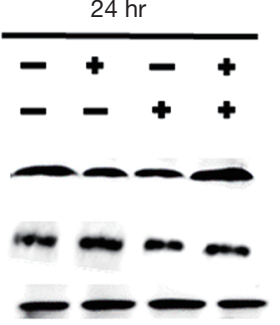

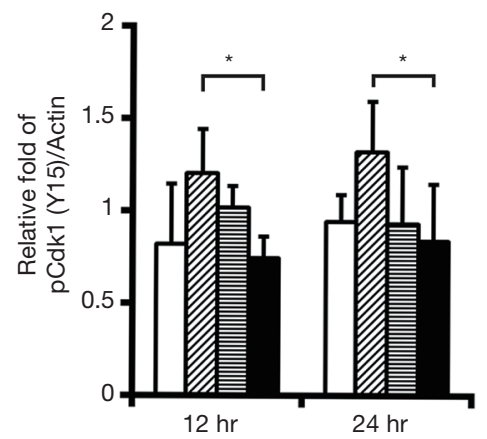

Figure 5 CINN decreased TMZ-induced G2/M arrest in human glioma cells. (A) U87 MG cells were pretreated with or without CINN $(50 \mu \mathrm{M})$ for $1 \mathrm{~h}$ and then with TMZ $(100 \mu \mathrm{M})$ for $72 \mathrm{~h}$. The effects of TMZ, CINN, and TMZ + CINN on the cell cycle were determined by DNA flow cytometry. $\mathrm{n}=3$ for U87 MG cell lines. (B) The combined treatment of CINN and TMZ affected the G2/M checkpoint in human glioma cells. U87 MG cells were pretreated with or without CINN (50 $\mu \mathrm{M})$ for $1 \mathrm{~h}$, followed by TMZ (100 $\mu M)$. The protein expression of cyclin B in U87 MG cells was determined by western blotting. Combined treatment of TMZ and CINN considerably increased cyclin B expression in U87 MG cells. *, $\mathrm{P} \leq 0.05$ compared with vehicle-treated cells; ${ }^{*}, \mathrm{P} \leq 0.05$ compared with TMZ-treated cells. $\mathrm{n}=5$ for U87 MG cells. 


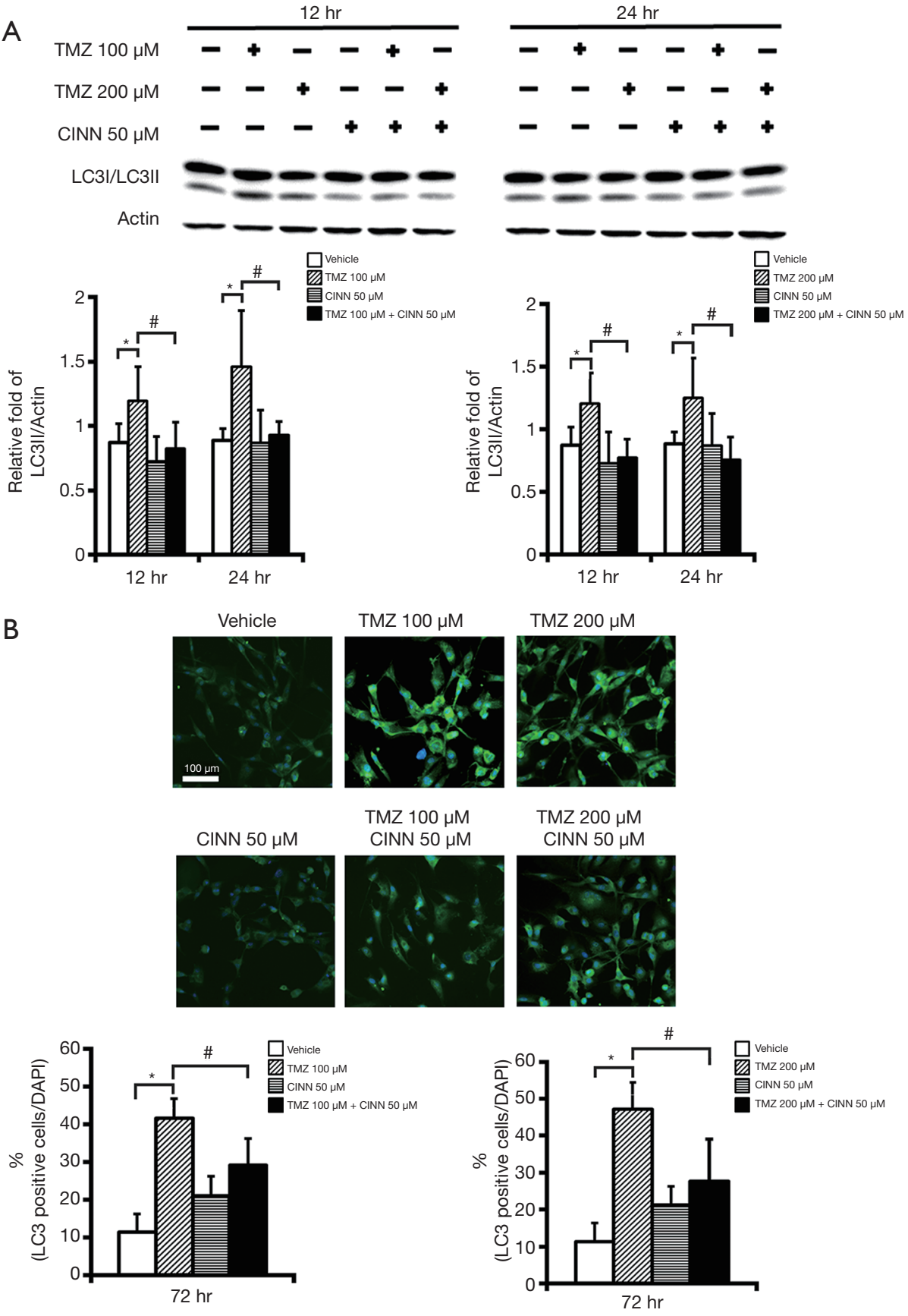

Figure 6 CINN reduced TMZ-induced autophagy in human glioma cells. (A) U87 MG cells were pretreated with or without CINN $(50 \mu \mathrm{M})$ for $1 \mathrm{~h}$, followed by TMZ (100 or $200 \mu \mathrm{M})$. $\beta$-actin was used as an internal control to normalize the number of proteins applied in each lane. The protein expression of LC3 in U87 MG cells was determined at the indicated times. (B) LC3 expression in U87 MG cells was observed by immunofluorescence staining (blue: DAPI, green: LC 3, 400×). *, P $\leq 0.05$ compared with vehicle-treated cells; ${ }^{*}$, P $\leq 0.05$ compared with TMZ-treated cells. $\mathrm{n}=6$ for U87 MG cells. 
to improve the efficacy of cytotoxicity as the overall survival rate is low in the management of GBM, and most patients eventually develop drug resistance to standard TMZ therapy. Here, we revealed that CINN at a concentration of $50 \mu \mathrm{M}$ enhanced TMZ-induced cytotoxicity in glioma cells. The combined administration of CINN and TMZ at $100 \mu \mathrm{M}$ exerted a potent antitumor action in the glioma cell line U87 MG in a dose-dependent manner (Figure 2). The enhancement of cytotoxicity against tumor growth in the xenograft animal model treated with CINN plus TMZ further demonstrated combined treatment of CINN and TMZ more effective than TMZ only in vivo. Our previous studies have shown that CINN can pass through the bloodbrain barrier and is removed gradually in the brain (22). A low dose of CINN $(10 \mu \mathrm{M})$ alone exerted antiapoptotic effects to protect neurons against ischemic stroke by suppressing oxidative stress in the cerebrum in an animal model (22). Thus, combined treatment of CINN and TMZ may be effective in treating patients with GBM.

The mechanism by which CINN protects neuronal cells against ischemia-reperfusion is linked to its ability to scavenge ROS and reduce ROS-induced apoptosis $(21,22)$. ROS can exert numerous effects depending on the signaling pathway they regulate (32). We examined whether the suppression of ROS by CINN might affect TMZ-induced cytotoxicity, and found that the reduction of ROS enhanced TMZ-induced cytotoxicity and not lower it. In a study on resveratrol, TMZ-induced ROS burst was maximum at $2-3$ days in glioma cell lines $(8,9)$. TMZ-induced ROS burst is a protective signal that helps glioma cells escape apoptotic cell death, and the antioxidant resveratrol enhances the cytotoxicity of TMZ by reducing ROS (9). Our data are consistent with those of these previous studies on resveratrol, that is, treatment with the antioxidant CINN $(50 \mu \mathrm{M})$ for $1 \mathrm{~h}$ completely abolished TMZinduced ROS production at $72 \mathrm{~h}$. Our group has previously shown that CINN effectively inhibits $\mathrm{Fe} 3+-$ induced lipid peroxidation, which is superior to vitamin $\mathrm{E}$ and $\beta$-estradiol. In the 2,2'-azino-bis(3-ethylbenzothiazoline-6-sulfonate) (ABTS) radical cation scavenging assay, the $\mathrm{IC}_{50}$ value of $\mathrm{CINN}$ was $11.2 \mu \mathrm{M}$, which is higher than that of vitamin $\mathrm{C}$ $\left(\mathrm{IC}_{50}=23.3 \mu \mathrm{M}\right)(21)$. Moreover, we previously reported that $50 \mu \mathrm{M}$ CINN inhibited more than $50 \%$ of phorbol 12-myristate 13 -acetate-induced $\mathrm{O}_{2}{ }^{-}$and $\mathrm{H}_{2} \mathrm{O}_{2}$ production in neutrophils (29). Here, TMZ treatment caused the accumulation of ROS, including $\mathrm{O}_{2}{ }^{-}$and $\mathrm{H}_{2} \mathrm{O}_{2}$. The source of ROS is mainly the mitochondria owing to the operation of the respiratory chain, and excessive ROS can damage mitochondria, resulting in cytoprotective autophagy $(8,33)$. Our findings concur with those of Lin et al., in that, antioxidants, such as CINN and resveratrol, may elevate TMZ-induced cytotoxicity by inhibiting ROS burst in glioma cell lines. Our previous studies demonstrated that CINN can inhibit ROS burst by reducing $\mathrm{O}_{2}{ }^{-}$and $\mathrm{H}_{2} \mathrm{O}_{2}$ production $(21,22,29)$.

Several studies have reported that the activation of G2 arrest provides time for glioma DNA repair during the treatment of TMZ (10). We previously indicated that grade III and grade IV gliomas have higher G2/M-phase and S+G2/M-phase fractions than grade I/II gliomas, which implies that G2/M may be associated with the severity of GBM (34). Hirose and colleagues indicated that TMZ induces $\mathrm{G} 2 / \mathrm{M}$ arrest in glioma cells, and inhibition of the G2 checkpoint pathway enhances cytotoxicity (35). Studies on adjuvant treatment with resveratrol and TMZ have shown that TMZ-induced G2 arrest is inhibited (11). The induction of G2 arrest by pretreatment with TMZ for $48 \mathrm{~h}$ is not reversed by resveratrol, suggesting that resveratrol suppresses TMZ-induced downstream signaling that causes G2 arrest (11). As TMZ-induced ROS accumulation increased in the first $48 \mathrm{~h}$ after the treatment, it is plausible that TMZ-induced ROS was responsible for the induction of G2 arrest. We provided evidence consistent with the notion that the combined treatment of CINN and TMZ enhanced the efficacy of TMZ by inhibiting G2/M arrest via the inhibition of TMZ-induced ROS burst.

Following the treatment of glioma cells with TMZ, the G2 checkpoint in the cell cycle exhibited two distinct effects on cells following DNA damage: (I) arrest of cells in the G2 phase and (II) triggering of cytoprotective activity, which results in resistance to TMZ. TMZ was previously reported to play a critical role in the autophagy system; it might lead the cell into a pro-survival or pro-apoptotic situation $(19,36)$. Our results showed that LC3 protein level, a hallmark of autophagy, was increased in TMZ-treated U87 MG cells. However, combined treatment of TMZ and CINN lowered LC3-II protein expression after 12 and $24 \mathrm{~h}$ compared with TMZ alone. Immunofluorescence staining also revealed a reduction in LC3 protein level when U87 MG cells were treated with a combination of TMZ and CINN. We illustrated that CINN suppressed TMZ-induced autophagy, although the levels of Beclin 1 and p21 were not investigated in our study.

In conclusion, TMZ-induced ROS production in glioma cells was reduced when cells were pretreated with the antioxidant CINN. CINN treatment increased the 
cytotoxicity of TMZ, which may have resulted from a decrease in G2/M arrest and an increase in apoptotic cell death. The combination of CINN and TMZ could be of potential clinical interest for the management of GBM.

\section{Acknowledgments}

We thank the ministry of science and technology and office of Research-Animal Care of national Cheng Kung University for research permission.

Funding: The financial support was provided by the ministry of science and technology in Taiwan (106-2314-B-006-031).

\section{Footnote}

Reporting Checklist: The authors have completed the ARRIVE reporting checklist. Available at https://dx.doi. org/10.21037/tcr-20-3426

Data Sharing Statement: Available at https://dx.doi. org/10.21037/tcr-20-3426

Conflicts of Interest: All authors have completed the ICMJE uniform disclosure form (available at https://dx.doi. org/10.21037/tcr-20-3426). All authors report that the financial support was provided by the ministry of science and technology in Taiwan. The authors have no other conflicts of interest to declare.

Ethical Statement: The authors are accountable for all aspects of the work in ensuring that questions related to the accuracy or integrity of any part of the work are appropriately investigated and resolved. Animal experiments were approved by and conducted under the strict guidelines of the Subcommittee on Research-Animal Care of NCKU University Medical Center (approval no. 106112), and the standards met the guidelines for the care and use of animals of Taiwan National Institutes of Health.

Open Access Statement: This is an Open Access article distributed in accordance with the Creative Commons Attribution-NonCommercial-NoDerivs 4.0 International License (CC BY-NC-ND 4.0), which permits the noncommercial replication and distribution of the article with the strict proviso that no changes or edits are made and the original work is properly cited (including links to both the formal publication through the relevant DOI and the license). See: https://creativecommons.org/licenses/by-nc-nd/4.0/.

\section{References}

1. Witthayanuwat S, Pesee M, Supaadirek C, et al. Survival Analysis of Glioblastoma Multiforme. Asian Pac J Cancer Prev 2018;19:2613-7.

2. Nizamutdinov D, Stock EM, Dandashi JA, et al. Prognostication of Survival Outcomes in Patients Diagnosed with Glioblastoma. World Neurosurg 2018;109:e67-74.

3. Darefsky AS, King JT Jr, Dubrow R. Adult glioblastoma multiforme survival in the temozolomide era: a populationbased analysis of Surveillance, Epidemiology, and End Results registries. Cancer 2012;118:2163-72.

4. Ramirez YP, Weatherbee JL, Wheelhouse RT, et al. Glioblastoma multiforme therapy and mechanisms of resistance. Pharmaceuticals (Basel) 2013;6:1475-506.

5. Yan Y, Xu Z, Dai S, et al. Targeting autophagy to sensitive glioma to temozolomide treatment. J Exp Clin Cancer Res 2016;35:23.

6. Happold C, Stojcheva N, Silginer M, et al. Transcriptional control of O6 -methylguanine DNA methyltransferase expression and temozolomide resistance in glioblastoma. J Neurochem 2018;144:780-90.

7. Nakada M, Furuta T, Hayashi Y, et al. The strategy for enhancing temozolomide against malignant glioma. Front Oncol 2012;2:98.

8. Lin CJ, Lee CC, Shih YL, et al. Inhibition of mitochondriaand endoplasmic reticulum stress-mediated autophagy augments temozolomide-induced apoptosis in glioma cells. PLoS One 2012;7:e38706.

9. Lin CJ, Lee CC, Shih YL, et al. Resveratrol enhances the therapeutic effect of temozolomide against malignant glioma in vitro and in vivo by inhibiting autophagy. Free Radic Biol Med 2012;52:377-91.

10. Pawlowska E, Szczepanska J, Szatkowska M, et al. An Interplay between Senescence, Apoptosis and Autophagy in Glioblastoma Multiforme-Role in Pathogenesis and Therapeutic Perspective. Int J Mol Sci 2018;19:889.

11. Filippi-Chiela EC, Thomé MP, Bueno e Silva MM, et al. Resveratrol abrogates the temozolomide-induced G2 arrest leading to mitotic catastrophe and reinforces the temozolomide-induced senescence in glioma cells. BMC Cancer 2013;13:147.

12. Ito $M$, Ohba S, Gaensler K, et al. Early Chk1 phosphorylation is driven by temozolomide-induced, DNA double strand break- and mismatch repair-independent DNA damage. PLoS One 2013;8:e62351. 
13. Piret B, Schoonbroodt S, Piette J. The ATM protein is required for sustained activation of NF-kappaB following DNA damage. Oncogene 1999;18:2261-71.

14. Knizhnik AV, Roos WP, Nikolova T, et al. Survival and death strategies in glioma cells: autophagy, senescence and apoptosis triggered by a single type of temozolomide-induced DNA damage. PLoS One 2013;8:e55665.

15. Tomicic MT, Meise R, Aasland D, et al. Apoptosis induced by temozolomide and nimustine in glioblastoma cells is supported by JNK/c-Jun-mediated induction of the $\mathrm{BH} 3$-only protein BIM. Oncotarget 2015;6:33755-68.

16. Gratas C, Séry Q, Rabé M, et al. Bak and Mcl-1 are essential for Temozolomide induced cell death in human glioma. Oncotarget 2014;5:2428-35.

17. Würstle S, Schneider F, Ringel F, et al. Temozolomide induces autophagy in primary and established glioblastoma cells in an EGFR independent manner. Oncol Lett 2017;14:322-8.

18. Çıtışlı V, Dodurga Y, Eroğlu C, et al. Temozolomide may induce cell cycle arrest by interacting with URG4/ URGCP in SH-SY5Y neuroblastoma cells. Tumour Biol 2015;36:6765-72.

19. Lo Dico A, Salvatore D, Martelli C, et al. Intracellular Redox-Balance Involvement in Temozolomide ResistanceRelated Molecular Mechanisms in Glioblastoma. Cells 2019;8:1315.

20. Chen TY, Tai SH, Lee EJ, et al. Cinnamophilin offers prolonged neuroprotection against gray and white matter damage and improves functional and electrophysiological outcomes after transient focal cerebral ischemia. Crit Care Med 2011;39:1130-7.

21. Lee EJ, Chen HY, Hung YC, et al. Therapeutic window for cinnamophilin following oxygen-glucose deprivation and transient focal cerebral ischemia. Exp Neurol 2009;217:74-83.

22. Lee EJ, Chen HY, Lee MY, et al. Cinnamophilin reduces oxidative damage and protects against transient focal cerebral ischemia in mice. Free Radic Biol Med 2005;39:495-510.

23. Fang L, Gao H, Zhang W, et al. Resveratrol alleviates nerve injury after cerebral ischemia and reperfusion in mice by inhibiting inflammation and apoptosis. Int J Clin Exp Med 2015;8:3219-26.

24. Ding WQ, Liu B, Vaught JL, et al. Clioquinol and docosahexaenoic acid act synergistically to kill tumor cells.
Mol Cancer Ther 2006;5:1864-72.

25. Torres S, Lorente M, Rodríguez-Fornés F, et al. A combined preclinical therapy of cannabinoids and temozolomide against glioma. Mol Cancer Ther 2011;10:90-103.

26. Lu HF, Lai TY, Hsia TC, et al. Danthron induces DNA damage and inhibits DNA repair gene expressions in GBM 8401 human brain glioblastoma multiforms cells. Neurochem Res 2010;35:1105-10.

27. Alan Mitteer R, Wang Y, Shah J, et al. Proton beam radiation induces DNA damage and cell apoptosis in glioma stem cells through reactive oxygen species. Sci Rep 2015;5:13961.

28. Juan WS, Huang SY, Chang CC, et al. Melatonin improves neuroplasticity by upregulating the growthassociated protein-43 (GAP-43) and NMDAR postsynaptic density-95 (PSD-95) proteins in cultured neurons exposed to glutamate excitotoxicity and in rats subjected to transient focal cerebral ischemia even during a long-term recovery period. J Pineal Res 2014;56:213-23.

29. Lin YW, Tai SH, Tien CH, et al. Cinnamophilin Inhibits Neutrophilic Respiratory Burst and Protects Against Ischemia-Reperfusion Brain Damage. Pharm Anal Acta 2013;4:1-6.

30. Verbon EH, Post JA, Boonstra J. The influence of reactive oxygen species on cell cycle progression in mammalian cells. Gene 2012;511:1-6.

31. Li Y, Qin Y, Yang C, et al. Cardamonin induces ROSmediated G2/M phase arrest and apoptosis through inhibition of NF- $\kappa$ B pathway in nasopharyngeal carcinoma. Cell Death Dis 2017;8:e3024.

32. Azad MB, Chen Y, Gibson SB. Regulation of autophagy by reactive oxygen species (ROS): implications for cancer progression and treatment. Antioxid Redox Signal 2009;11:777-90.

33. Gao M, Yeh PY, Lu YS, et al. OSU-03012, a novel celecoxib derivative, induces reactive oxygen speciesrelated autophagy in hepatocellular carcinoma. Cancer Res 2008;68:9348-57.

34. Lin YW, Tai SH, Chang CC, et al. Application of flow cytometry for evaluating clinical prognosis and histopathological grade of human glioma. Neurol Res 2016;38:625-33.

35. Hirose Y, Katayama M, Mirzoeva OK, et al. Akt activation suppresses Chk2-mediated, methylating agent-induced G2 arrest and protects from temozolomide-induced 
mitotic catastrophe and cellular senescence. Cancer Res 2005;65:4861-9.

36. Kanzawa T, Germano IM, Komata T, et al. Role of autophagy in temozolomide-induced cytotoxicity for malignant glioma cells. Cell Death Differ 2004;11:448-57.

Cite this article as: Tai SH, Lin YW, Huang TY, Chang CC, Chao LC, Wu TS, Lee EJ. Cinnamophilin enhances temozolomide-induced cytotoxicity against malignant glioma: the roles of ROS and cell cycle arrest. Transl Cancer Res 2021;10(9):3906-3920. doi: 10.21037/tcr-20-3426 